\title{
Quality of Life Following Prestige LP Cervical Disc Arthroplasty in a Prospective Multicountry Study
}

\author{
JAN STULIK, MD, ${ }^{1}$ MARTON RONAI, MD ${ }^{2}$ BRUNO RUDINSKY, MD, ${ }^{3}$ DANIEL ZARZYCKI, MD, ${ }^{4}$ \\ DARIUSZ LATKA, MD, ${ }^{5}$ JIRI MATEJKA, MD, ${ }^{6}$ SALEH BAEESA, MD, FRCSC, FAANS ${ }^{7}$ \\ ${ }^{I}$ Department of Spondylosurgery, University Clinic Motol, Praha, Czech Republic, ${ }^{2}$ Department of Orthopaedics, National Center for Spinal Disorders, Budapest, \\ Hungary, ${ }^{3}$ Department of Neurosurgery, Faculty Hospital Nové Zámky, Slovakia, ${ }^{4}$ Department of Orthopaedic and Rehabilitation, Jagiellonian Uniniversity \\ Hospital, Zakopane, Poland, ${ }^{5}$ Department of Neurosurgery, Opole University, Institute of Medicine, University Hospital, Poland, ${ }^{6}$ Department of Orthopaedics \\ and Traumatology of the Locomotor System of the Medical Faculty and the University Hospital in Pilsen, Plzen, Czech Republic, ${ }^{7}$ Division of Neurosurgery, \\ Faculty of Medicine, King Abdulaziz University, Jeddah, Saudi Arabia
}

\begin{abstract}
Background: To describe routine surgical practice using Prestige LP Cervical Disc (Prestige disc) and patient outcomes for degenerative cervical disc disease in a multicenter 2-year prospective, observational study.

Methods: Patient demographics and intraoperative data were collected; quality of life (QoL) (EQ-5D, EQ-VAS, and neck disability index), average disc height, and adverse events were assessed pre- and postoperatively at 3, 6, 12, and 24 months.

Results: One hundred and ninety-four patients were enrolled (190 patients implanted; female: 67\%; mean age: 44.0 years; mean body mass index: 25.6). Disc herniation was the most frequent indication for cervical arthroplasty $(80.5 \%)$. Thirty-seven percent of patients experienced pain for $>1$ year prior to baseline assessment. Mean procedure duration was 87.1 minutes, and mean blood loss was $43.8 \mathrm{~mL}$. The majority $(71.0 \%)$ of Prestige discs were implanted at level C5 to C6, while $16.3 \%$ of patients received implants at 2 levels. There was a significant improvement from baseline to 3, 6, 12, and 24 months of follow-up in all QoL assessments. After implantation, the mean disc height at the affected level increased by 0.19 from baseline (0.22) to 3 months $(0.41)$ and remained constant up to 24 months $(P<.001)$. Mean disc height of levels above and below the implant remained comparable at baseline and follow-up. A total of 63 adverse events (44 patients) was recorded, of which 7 (11.1\%) were related to the Prestige disc, instrumentation, or procedure; 41 $(65.1 \%)$ were unrelated; and $15(23.8 \%)$ had an unknown relation.
\end{abstract}

Conclusions: In line with published findings, our study shows significant improvement in outcomes in the first 3 months after Prestige disc implantation with improvements maintained throughout the study.

Cervical Spine

Keywords: cervical spine, degenerative disc disease, arthroplasty, Prestige LP Cervical Disc, quality of life

\section{INTRODUCTION}

Traditional cervical surgical decompressions and fusions are the most common treatment option in patients with degenerative disc disease. Anterior cervical discectomy and fusion has been the standard therapy for many years. However, despite good treatment success rates, fusions can alter the normal kinematics of the spine (ie, limit the range of motion and cause subsequent development of adjacent segment degeneration) and can have related complications and pain. ${ }^{1-3}$ Total disc replacement using an artificial disc may therefore provide an alternative solution for patients suffering from degenerative disc disease to preserve motion in the affected level. ${ }^{4}$
This prospective observational study examined the use of the Prestige LP Cervical Disc system (Prestige disc) in patients with degenerative disc disease in central and eastern Europe and the Middle East.

\section{MATERIALS AND METHODS}

This was a prospective, multicountry, noninterventional, postmarketing study in patients scheduled for an implant of a Prestige disc for degenerative disc disease and fulfilling the indications according to the product description. The study was conducted in compliance with the study plan, local laws, and the Declaration of Helsinki.

The primary objective was the documentation of quality of life (QoL) before and after cervical disc 
surgery using the Prestige disc. QoL was assessed using the EQ-5D and the neck disability index (NDI).

Secondary objectives were the documentation of duration of pain prior to enrollment; average disc height of the affected and adjacent disc levels; implantation data, such as size of cervical disc prosthesis, operation time, and blood loss; and heterotopic ossification (HO) throughout the course of the study. Tertiary objectives were collection of adverse events (AEs) and surgeons' perception throughout the course of the study, together with the economic considerations of hospital stay and time back to work.

\section{Eligibility Criteria}

To be eligible for the study, patients had to sign a study-specific data release form and agree to undergo surgery and evaluations according to hospital routine. Visits were scheduled at 3 months (visit date between implant and 4.5 months after surgery), 6 months (4.5-9 months), 12 months (9-18 months), and 24 months (more than 18 months postsurgery). Patients were excluded if they had not reached the age of legal consent according to local laws, fulfilled any contraindication according to the product description, had diabetes, had a body mass index greater than 35 , had affected disc not between $\mathrm{C} 3 / \mathrm{C} 4$ and $\mathrm{C} 6 / \mathrm{C} 7$, had cervical instability, or were going to receive extensive decompression.

\section{Clinical Evaluations}

At enrollment (baseline), demographics, primary indication, general health status, affected disc level, and time of pain prior to enrollment were documented. In addition to these parameters, radiological evaluations were performed at enrollment and at follow-up visits together with documentation of concomitant medication and QoL, collected using the EQ-5D (http://www.euroqol.org), ${ }^{5}$ the NDI, ${ }^{6}$ and the visual analog scale (VAS) for neck and arm pain.

Investigator perception of the surgery outcome, classified as having poor, fair, good, very good, or excellent outcome, was collected at the follow-up visits. Information on the implantation device was recorded together with skin-skin time and blood loss at implantation. AEs were recorded throughout the course of the study.

\section{Radiographic Evaluations}

All radiological evaluations were performed by the participating site. Intervertebral disc space of the affected and adjacent disc levels was assessed in radiological images taken in the neutral position. The intervertebral disc height, measured as average disc height, was calculated as $[(\mathrm{A}+\mathrm{B}) / 2] / \mathrm{H}$, where $\mathrm{A}$ is the posterior intervertebral disc height, $\mathrm{B}$ is the anterior intervertebral disc height, and $\mathrm{H}$ is the anterior height of the upper vertebral body. ${ }^{7}$ Range of movement was documented by radiographic evaluation.

$\mathrm{HO}$ was documented postoperatively throughout the course of the study on a scale between 0 and 4 : no $\mathrm{HO}$ present $(0)$. HO detectable in front of the vertebral body but not in the anatomic intervertebral space (I). HO growing into the disc space with possible affection of the function of the prosthesis (II). bridging ossifications that still allow movement of the prosthesis (III), and complete fusion of the treated segment without movement in flexion or extension (IV). ${ }^{8,9}$

\section{STATISTICAL METHODS}

Patients' demographics and characteristic categorical variables were analyzed by descriptive statistics. For continuous variables, mean values and standard deviations were calculated. For categorical variables, frequencies were calculated. The denominator for percentages was the number of nonmissing values. Relative frequencies were based on available observations (excluding missing values). For change from baseline analysis, when both baseline and follow-up data were known, the change from baseline was computed as follow-up assessment - baseline assessment. A 95\% confidence interval was given, together with the descriptive statistics of continuous variables. $P$ values for paired comparison for the changes from preoperative to the follow-up visits were generated using a paired $t$ test.

\section{RESULTS}

\section{Patient Demographics}

One hundred and ninety-four patients with degenerative disc disease were enrolled in the study: 190 patients met the inclusion criteria, and 148 $(77.9 \%)$ patients completed the last study follow-up visit at 24 months after implant (Figure 1). Four 


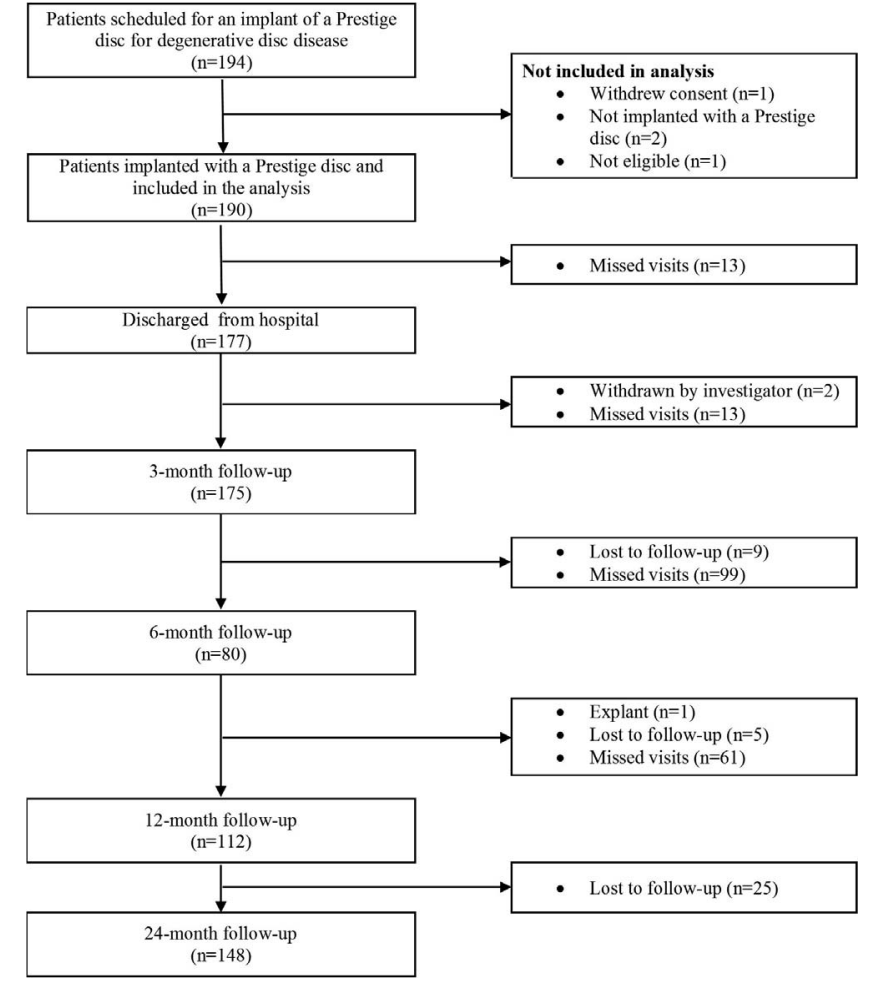

Figure 1. Study flowchart.

patients were excluded from the analysis for the following reasons: 1 patient withdrew consent, 2 patients did not receive the Prestige disc, and 1 patient violated the exclusion criterion (affected disc not between $\mathrm{C} 3 / \mathrm{C} 4$ and $\mathrm{C} 6 / \mathrm{C} 7$ ) and was excluded from the study by the investigator. The patients were enrolled at 15 sites in the Czech Republic ( $\mathrm{n}=$ 44), Hungary $(\mathrm{n}=13)$, Kuwait $(\mathrm{n}=1)$, Poland $(\mathrm{n}=$ 86), Serbia $(\mathrm{n}=11)$, Saudi Arabia $(\mathrm{n}=11)$, and Slovakia $(n=28)$. The demographic and clinical characteristics of these patients are summarized in Table 1. Almost two-thirds $(66.9 \%)$ of the 190 analyzed patients were female, with an average patient age of $43.9 \pm 8.6$ years (mean \pm SD) and an average body mass index (BMI) of $25.6 \pm 4.1$

Table 1. Patient demographics and clinical characteristics before surgery.

\begin{tabular}{|c|c|}
\hline Variable & Value, $\mathbf{n}=190$ \\
\hline Gender (male/female), no. (\%) & $63(33.1) / 127(66.9)$ \\
\hline Age, years, mean $\pm \mathrm{SD}$ (range) & $43.95 \pm 8.6(26-66)$ \\
\hline BMI, mean \pm SD (range) & $25.6 \pm 4.1(17-37)$ \\
\hline \multicolumn{2}{|l|}{ Duration of pain prior to baseline visit, no. (\%) } \\
\hline No pain & $1(0.5)$ \\
\hline $0-3$ months prior to baseline & $35(18.4)$ \\
\hline 3-6 months prior to baseline & $42(22.1)$ \\
\hline $6-12$ months prior to baseline & 41 (21.6) \\
\hline$>12$ months prior to baseline & $71(37.4)$ \\
\hline Patients with previous cervical surgeries & $11(6.1)$ \\
\hline Patients with concomitant diseases at baseline & $134(70.5)$ \\
\hline
\end{tabular}

Abbreviation: BMI, body mass index.
(Table 1). A substantial portion of patients (37.4\%) reported pain duration of more than 1 year prior to baseline. One patient $(0.5 \%)$ did not suffer from pain prior to baseline and was operated on based on radiological findings. Eleven patients $(6.1 \%)$ had previous cervical surgery (cervical fusion procedures $[n=6]$, corpectomy $[n=1]$, transient stabilization [ $\mathrm{n}$ $=1]$, and thyroidectomy $[\mathrm{n}=3])$. For the vast majority of the patients, the primary indication for cervical disc replacement was disc herniation $(80.5 \%)$. Cervical spondylosis and osteophyte formation were the primary indication for disc replacement in $7.9 \%$ and $6.3 \%$ of the patients, respectively. Ten patients $(5.3 \%)$ had other primary indications for disc replacement.

Seven patients did not meet all inclusion and exclusion criteria: 4 patients had diabetes, 1 patient had a BMI $>35,1$ patient had diabetes and BMI $>$ 35 , and 1 patient was receiving extensive decompression. These patients were included in the analysis, as diabetes and extensive decompression are not contraindications according to the Prestige disc instructions for use. The same holds true for BMI > 35 even though morbid obesity is a contraindication. These patients were therefore treated at the discretion of the treating surgeon.

One hundred and forty-eight patients $(77.9 \%)$ completed the last study follow-up at 24 months (Figure 1). Of the 42 patients who did not complete the study. 39 patients were lost to follow-up, 2 patients were withdrawn from the study by the investigator after discharge as the patients did not return for their scheduled follow-ups, and 1 patient had the Prestige disc explanted 5 months after implantation due to recurrence of neck pain.

\section{Surgery Data}

For the 190 patients implanted, mean operative time was 87.1 minutes (SD: 45.2 minutes; range: 30 to 225 minutes; $\mathrm{n}=190$ ), and mean blood loss was $43.8 \mathrm{~mL}$ (SD: 64.4; range: 30 to $600 \mathrm{~mL}$; $\mathrm{n}=189$ ). Further, $159(83.7 \%)$ patients received implants in 1 level, and $31(16.3 \%)$ received implants in 2 levels (total of 221 implants). Overall, including singleand double-level implants, C5/C6 was the level most frequently implanted (135 implants, $71.0 \%$ ), followed by C6/C7 (50 implants, 26.3\%), C4/C5 (33 implants, $17.4 \%$ ), and $\mathrm{C} 3 / \mathrm{C} 4$ (3 implants, $1.6 \%$ ). Most patients with single-level implants were implanted in C5/C6 (104 patients, 54.8\%) followed by C6/C7 (37 patients, 19.5\%), C4/C5 (16 patients, 


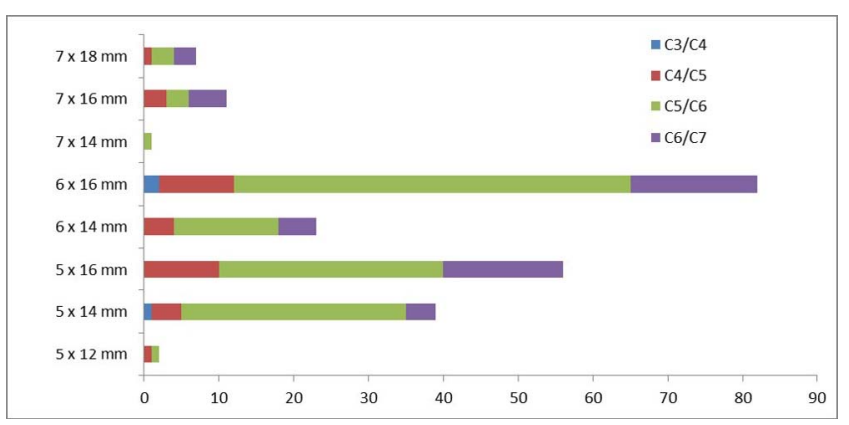

Figure 2. Number of Prestige discs implanted by size and implanted level $(\mathrm{n}=$ 221).

$8.4 \%$ ), and $\mathrm{C} 3 / \mathrm{C} 4$ (2 patients, $1.0 \%$ ). Most patients with double level implants were implanted in $\mathrm{C} 4 / \mathrm{C} 5$ $+\mathrm{C} 5 / \mathrm{C} 6$ (17 patients, $9.0 \%$ ), followed by $\mathrm{C} 5 / \mathrm{C} 6+$ $\mathrm{C} 6 / \mathrm{C} 7(50$ patients, $6.8 \%)$ and $\mathrm{C} 3 / \mathrm{C} 4+\mathrm{C} 5 / \mathrm{C} 6(1$ patient, $0.5 \%)$.

Although the Prestige disc is available in 13 different sizes, only 8 different sizes were implanted (Figure 2). The size most frequently implanted was 6 $\times 16 \mathrm{~mm}$ (82 implants, $37.0 \%$ ) followed by $5 \times 16$ mm (56 implants, $25.3 \%), 5 \times 14 \mathrm{~mm}$ (39 implants, $17.6 \%)$, and $6 \times 14 \mathrm{~mm}$ (23 implants, $10.4 \%)$. The remaining implant sizes were used in $9.5 \%$ of the implants (21 implants). According to the investigators, the surgery outcome was good, very good, or excellent for most of the cases (Figure 3). This percentage remained stable for all follow-up visits: $96.5 \%$ at 3 months, $92.5 \%$ at 6 months, $92.8 \%$ at 12 months, and $88.4 \%$ at 24 months. There were no cases of poor outcome reported.

Following surgery, the median time to discharge from hospital was 3.0 days, with a mean of 4.8 days $( \pm 12.9)$ and a range of 1 to 116 days $(n=177)$. There was a slight decrease in the percentage of patients working at the time of surgery compared to those returning to work after surgery (from 59.3\% to $52.0 \%$ ) with $76.7 \%$ of those working at baseline

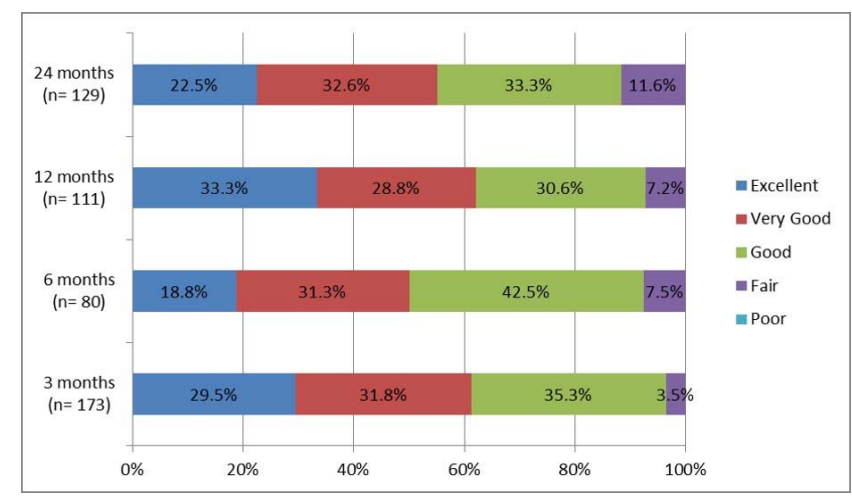

Figure 3. Investigator perception of the surgery outcome.
Table 2. Work status at baseline and return to work $(n=190)$.

\begin{tabular}{lr}
\hline Status & Value, no. $(\mathbf{\%})$ \\
\hline Baseline $(\mathrm{n}=189)$ & \\
Working & $112(59.3)$ \\
Not working & $53(28.0)$ \\
Retired & $24(12.7)$ \\
After surgery $(\mathrm{n}=175)$, all patients & $91(52.0)$ \\
$\quad$ Patient returned to work & $55(31.4)$ \\
Patient did not return to work & $29(16.6)$ \\
Not applicable & 29 \\
\hline
\end{tabular}

Abbreviation: n, number of patients.

returning to work (Table 2). The median time to return to work for all patients was 90.5 days, with a mean of 114.3 days $( \pm 116.1)$ and a range of 10 to 844 days $(n=86)$.

\section{Patient-Reported Outcomes: EQ-5D}

Mean EQ-5D index at baseline was 0.59 ( \pm 0.22$)$, and mean EQ-5D VAS was $51.7( \pm 19.5)$ (Table 3 ). At the 3-month follow-up, the values increased, respectively, to $0.78( \pm 0.16)$ and $72.9( \pm 18.1)$, resulting in a statistically significant increase $(P<$ $.001)$ of $0.20( \pm 0.24)$ points in EQ-5D index and $23.1( \pm 22.9)$ points in EQ-5D VAS. The statistically significant improvement in EQ-5D index and EQ5D VAS was maintained up to the 24-month followup. At this visit, EQ-5D index and EQ-5D VAS increased by $0.17( \pm 0.26)$ and $18.6( \pm 24.6)$ points, respectively, compared to baseline $(P<.001$ for both values).

At 24 months, the proportion of patients reporting no health-related problems increased from the preoperative values in each of the 5 individual EQ-5D dimensions: mobility $(67.2 \%$ versus $56.8 \%)$, self-care $(70.4 \%$ versus $53.5 \%)$, usual activities $(50.4 \%$ versus $15.5 \%)$, pain/discomfort $(27.0 \%$ versus $2.6 \%$ ), and anxiety/depression $(58.7 \%$ versus $34.8 \%$ ) (Figure 4). For each dimension, the improvement could be observed from the 3-month follow-up.

At the 3-month follow-up, 78.7\% (137 yes/37 no) of the patients had EQ-5D minimal clinically important difference (MCID), predefined as an improvement of 0.08 . This improvement remained constant at the follow-up visits: $76.3 \%(61 / 19)$ at 6 months, $68.2 \%(73 / 34)$ at 12 months, and $75.6 \%$ $(96 / 31)$ at 24 months.

\section{NDI}

The mean NDI at baseline was $24.1( \pm 8.6)$, which was reduced by $-11.2( \pm 10.4)$ to $13.2( \pm 8.9)$ at 3 months (Table 4). This reduction was maintained to 
Table 3. EQ-5D index and EQ-5D visual analog scale (VAS), together with change from baseline $(n=190) .{ }^{a}$

\begin{tabular}{|c|c|c|c|c|c|}
\hline \multirow[b]{2}{*}{ Variable } & \multicolumn{5}{|c|}{ Visit } \\
\hline & Baseline & $3 \mathrm{mo}$ & $6 \mathrm{mo}$ & $12 \mathrm{mo}$ & 24 mo \\
\hline EQ-5D index & $0.59 \pm 0.22(155)$ & $0.78 \pm 0.16(164)$ & $0.77 \pm 0.20(78)$ & $0.80 \pm 0.19(102)$ & $0.76 \pm 0.21(123)$ \\
\hline Change from baseline & - & $0.20 \pm 0.24(132)$ & $0.22 \pm 0.27(61)$ & $0.22 \pm 0.25(84)$ & $0.17 \pm 0.26(104)$ \\
\hline$P$ value & - & $<.001$ & $<.001$ & $<.001$ & $<.001$ \\
\hline EQ-5D VAS & $51.7 \pm 19.5(152)$ & $72.9 \pm 18.1(164)$ & $72.0 \pm 22.3(77)$ & $74.3 \pm 21.0(102)$ & $71.4 \pm 21.6(126)$ \\
\hline Change from baseline & - & $23.1 \pm 22.9$ & $22.4 \pm 24.8$ & $23.1 \pm 24.3$ & $18.6 \pm 24.6$ \\
\hline$P$ value & - & $<.001$ & $<.001$ & $<.001$ & $<.001$ \\
\hline
\end{tabular}

Abbreviation: $\mathrm{n}$, number of patients.

${ }^{\mathrm{a}}$ Results are written as mean $\pm \mathrm{SD}(\mathrm{n})$.

the last follow-up at 24 months $(-10.0 \pm 10.5)$. The improvement in NDI between baseline and followup was statistically significant $(P<.001)$ for all visits.

At the 3-month follow-up, $79.9 \%$ (131 yes/33 no) of the patients had NDI MCID, predefined as an improvement of 5 points in the NDI compared to baseline. This improvement reduced slightly at the follow-up visits: $73.1 \%(57 / 21)$ at 6 months, $69.9 \%$ $(72 / 31)$ at 12 months, and $73.0 \%(92 / 34)$ at 24 months.

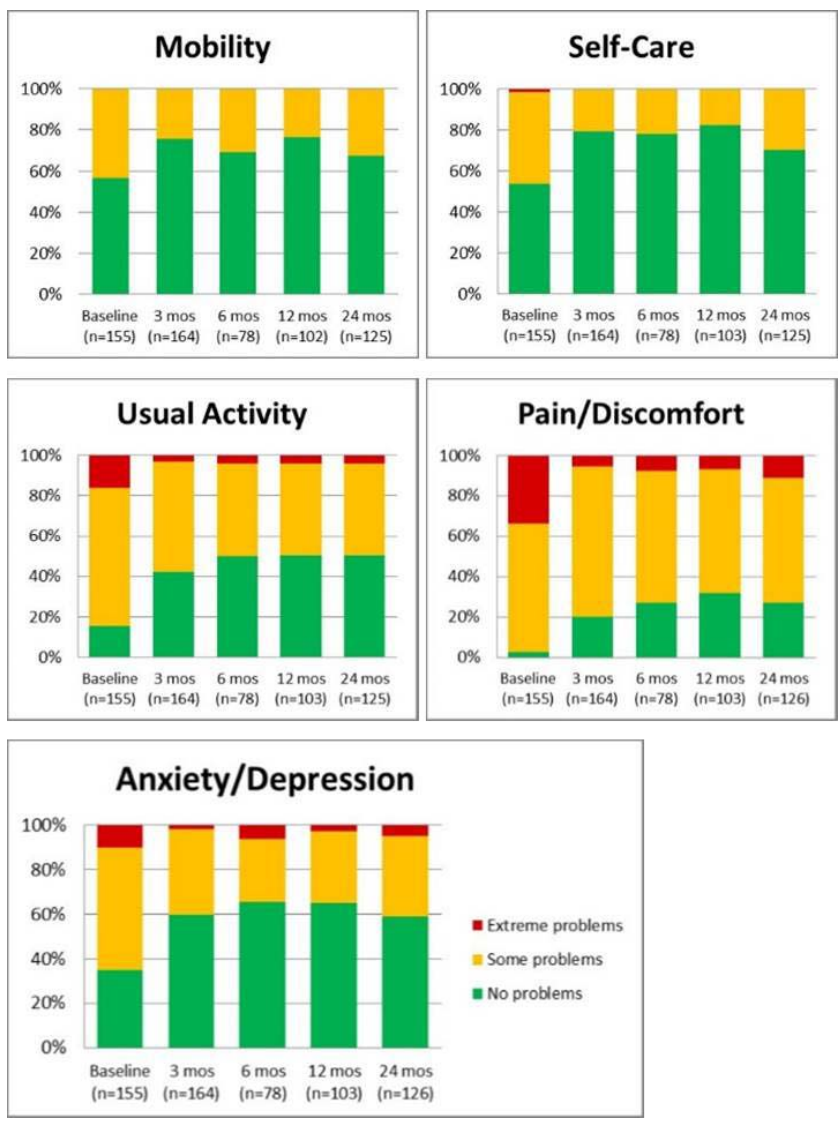

Figure 4. EQ-5D individual dimensions.

\section{Radiographic Outcomes}

The implant increased the average disc height at the affected level from $0.22( \pm 0.07)$ at baseline to 0.41 $( \pm 0.15)$ at the 3 -month follow-up, a change of 0.19 $( \pm 0.17)$ (Table 5, Figure 5). The statistically significant improvement $(P<.001)$ in average disc height was maintained to the 24-month follow-up. The average disc height of the levels above and below the implant remained comparable between baseline and follow-up visits. Device subsidence, defined as a decrease in average disc height at the affected level, was reported in $4.1 \%$ of patients and $4.8 \%$ of affected levels at 3 months and in $8.7 \%$ of patients and $6.5 \%$ of levels at 24 months (Table 6).

The percentage of patients without HO (grade 0) at the affected levels decreased over time following the 3-month follow-up. This was associated with the occurrence of HO grades III and IV at the 12- and 24-month follow-ups (Table 7).

\section{AEs}

Over the course of the study, 63 AEs were reported in 44 patients $(23.1 \%)$. From these, 8 events were serious $\mathrm{AE}$ ( 7 patients, 3.7\%), and 2 events were classified as serious adverse device effects (2 patients, $1.0 \%)$. Seven $(11.1 \%)$ of the reported

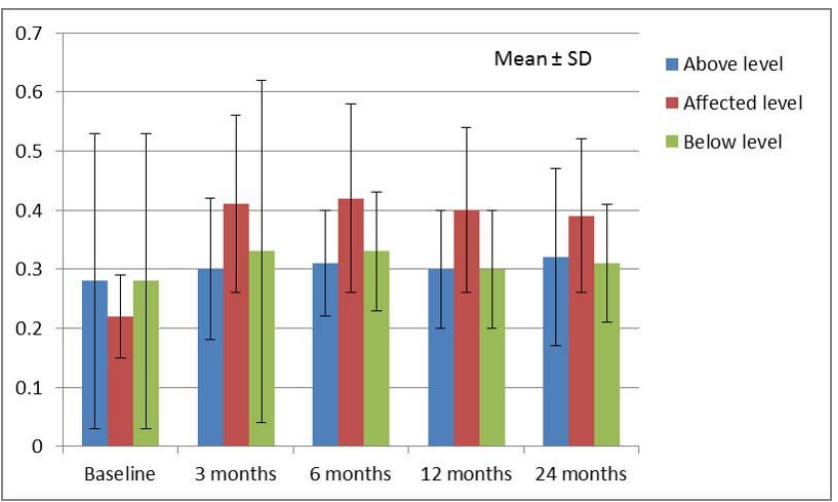

Figure 5. Intervertebral disc height measured as average disc height at affected and adjacent levels (mean $\pm \mathrm{SD}$ ). ${ }^{*} P$ value $<.05$, ${ }^{\star *} P$ value $<.001$. 
Table 4. Neck Disability Index score and change from baseline $(n=190){ }^{a}$

\begin{tabular}{lccccc}
\hline & \multicolumn{4}{c}{ Visit } \\
\cline { 2 - 6 } Variable & Baseline & $\mathbf{3}$ mo & $\mathbf{6}$ mo & $\mathbf{1 2}$ mo & $\mathbf{2 4}$ mo \\
\hline NDI & $24.1 \pm 8.6(155)$ & $13.2 \pm 8.9(164)$ & $12.6 \pm 10.2(78)$ & $12.3 \pm 10.0(103)$ & $13.4 \pm 10.3(126)$ \\
Change from baseline & - & $-11.2 \pm 10.4(132)$ & $-11.5 \pm 10.4(61)$ & $-12.0 \pm 11.0(85)$ & $-10.0 \pm 10.5(107)$ \\
$P$ value & - & $<.001$ & $<.001$ & $<.001$ & $<.001$ \\
\hline
\end{tabular}

Abbreviation: $n$, number of patients.

${ }^{\mathrm{a}}$ Results are written as mean $\pm \mathrm{SD}(\mathrm{n})$.

AEs were related to the Prestige disc, instrumentation, or procedure, while $41(65.1 \%)$ were not related, and $15(23.8 \%)$ had an unknown relation.

Actions taken as a result of the $\mathrm{AE}$ are given in Table 8. For the event where a visit to the emergency room was needed, the event was described by the investigator as "lumbar pain, L5/S1 discopathy" and reported as not related to the Prestige disc, instrumentation, or procedure. One Prestige disc was explanted 5 months after implantation surgery due to the recurrence of symptoms, and the level was fused. The investigator reported that the event was not related to the Prestige disc, instrumentation, or procedure and also reported no problem with the device structure or position. At the last patient follow-up, $48(77.4 \%)$ AEs were still ongoing, $10(16.1 \%)$ were resolved, and $4(6.5 \%)$ became a permanent condition. For 1 patient, no information on AE outcome was provided.

\section{DISCUSSION}

Implant of the Prestige disc in patients with degenerative disc disease resulted in a statistically significant improvement in QoL at 3 months, determined using the EQ-5D and NDI, and this was sustained up to the last follow-up visit at 24 months. The improvement in QoL was clinically relevant in $79.8 \%$ of patients, as defined as a 5-point improvement in NDI (MCID), and in more than
$70 \%$ of patients, as defined as a 0.08-point improvement in EQ-5D. Furthermore $88.4 \%$ of the investigators reported a surgery outcome of good, very good, or excellent at 24 months, with no cases of poor outcome reported.

A statistically significant improvement in NDI of 10.0 points, equivalent to a clinical improvement of $20 \%$, was reported at the 24-month follow-up. A US randomized study comparing Prestige disc with anterior cervical discectomy and fusion showed an improvement in NDI of $36.4 \%$ and $34.0 \%$, respectively, ${ }^{1}$ while two single-center studies in China and Singapore with the Prestige disc report NDI improvement of 13.8 points $^{10}$ and $27.0 \% .^{11}$ In central and eastern Europe, NDI improvements of $19.0 \%{ }^{12}$ and $7 \%{ }^{13}$ are reported for the ProDisc-C (Synthes USA), with the results from the current study falling within the reported range. An NDI improvement of $48.1 \%$ is observed 3 to 4 years after surgery with the ProDisc-C. ${ }^{14}$

We report a statistically significant increase in EQ-5D index of 0.17 points and EQ-5D VAS of 18.6 points at the 24 -month follow-up. Our data are within the range described previously: the SWISS spine group reported an increase of 0.40 point in EQ-5D index at the 24-month follow-up ${ }^{15}$ and an increase of 0.09 point in EQ-5D index and 19 points in EQ-5D Health Score for 7 patients undergoing cervical arthroplasty with ProDisc-C. ${ }^{16}$ For patients undergoing anterior cervical discectomy and fusion,

Table 5. Intervertebral disc measured as average disc height at affected and adjacent levels with change from baseline. ${ }^{a}$

\begin{tabular}{|c|c|c|c|c|c|}
\hline \multirow[b]{2}{*}{ Variable } & \multicolumn{5}{|c|}{ Visit } \\
\hline & Baseline & $3 \mathrm{mo}$ & $6 \mathrm{mo}$ & $12 \mathrm{mo}$ & 24 mo \\
\hline Affected level $(\mathrm{N}=221)$ & $0.22 \pm 0.07(96)$ & $0.41 \pm 0.15(98)$ & $0.42 \pm 0.16(62)$ & $0.40 \pm 0.14(64)$ & $0.39 \pm 0.13(46)$ \\
\hline Change from baseline & - & $0.19 \pm 0.17(62)$ & $0.19 \pm 0.19(41)$ & $0.18 \pm 0.15(48)$ & $0.16 \pm 0.14(31)$ \\
\hline$P$ value & & $<.001$ & $<.001$ & $<.001$ & $<.001$ \\
\hline Above level $(\mathrm{n}=190)$ & $0.28 \pm 0.25(111)$ & $0.30 \pm 0.12(123)$ & $0.31 \pm 0.09(62)$ & $0.30 \pm 0.10(62)$ & $0.32 \pm 0.15(89)$ \\
\hline $\begin{array}{l}\text { Change from baseline } \\
P \text { value }\end{array}$ & - & $\begin{array}{c}-0.01 \pm 0.29(83) \\
.788\end{array}$ & $\begin{array}{c}0.01 \pm 0.07(37) \\
.411\end{array}$ & $\begin{array}{c}0.01 \pm 0.07(38) \\
.344\end{array}$ & $\begin{array}{c}-0.01 \pm 0.34(57) \\
.753\end{array}$ \\
\hline Below level $(\mathrm{n}=190)$ & $0.28 \pm 0.25(85)$ & $0.33 \pm 0.29(90)$ & $0.33 \pm 0.10(42)$ & $0.30 \pm 0.10(42)$ & $0.31 \pm 0.10(65)$ \\
\hline $\begin{array}{l}\text { Change from baseline } \\
P \text { value }\end{array}$ & - & $\begin{array}{c}0.00 \pm 0.32(55) \\
.946\end{array}$ & $\begin{array}{c}0.05 \pm 0.10(24) \\
.017\end{array}$ & $\begin{array}{c}0.02 \pm 0.08(28) \\
.146\end{array}$ & $\begin{array}{c}-0.04 \pm 0.37(35) \\
.511\end{array}$ \\
\hline
\end{tabular}

Abbreviations: $n$, number of patients; $N$, number of levels.

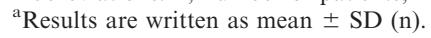


Table 6. Device subsidence. ${ }^{a}$

\begin{tabular}{|c|c|c|c|c|}
\hline \multirow[b]{2}{*}{ Device Subsidence } & \multicolumn{4}{|c|}{ Visit } \\
\hline & $3 \mathrm{mo}$ & $6 \mathrm{mo}$ & $12 \mathrm{mo}$ & $24 \mathrm{mo}$ \\
\hline $\mathrm{n}$ available (missing) & $62(159)$ & $41(180)$ & $48(173)$ & $31(190)$ \\
\hline $\begin{array}{l}\text { Affected levels with } \\
\text { device subsidence }\end{array}$ & $3(4.8)$ & $4(9.8)$ & $1(2.1)$ & $2(6.5)$ \\
\hline $\begin{array}{l}\text { Affected levels without } \\
\text { device subsidence }\end{array}$ & $59(95.2)$ & $37(90.2)$ & 47 (97.9) & $29(93.5)$ \\
\hline
\end{tabular}

Abbreviation: $\mathrm{n}$, number of patients.

${ }^{\text {a }}$ Results are written as $\mathrm{n}$ ( $\%$ available).

a 0.14-point increase in EQ-5D has been reported 12 months after surgery. ${ }^{17}$

One of the goals of cervical arthroplasty is to restore normal disc height. In this study, there was an increase in disc height at the affected level at 3 months after surgery, and the disc height remained constant thereafter. Disc height of the levels above and below the implant remained unchanged preand postsurgery, in line with results reported in the literature. $^{12}$

Device subsidence, defined as a decrease in average disc height at the affected level, was reported in $4.1 \%$ of patients and $4.8 \%$ of affected levels at 3 months and $8.7 \%$ of patients and $6.5 \%$ of affected levels at 24 months. Differences in the number of patients with subsidence among followup visits might be due to the fluctuations in the number of patients at each visit. We observed that $\mathrm{HO}$ was present in $44 \%$ of patients at the $24-$ month follow-up. This compares to the $8 \%$ to $16 \%$ incidence of $\mathrm{HO}$ reported after cervical arthroplasty ${ }^{10,18}$ but is lower than the $60 \%$ reported in a small retrospective study. ${ }^{19} \mathrm{HO}$ does not have a negative influence on the clinical outcome, as range of motion was not restricted at 7-year follow-up following cervical arthroplasty in a prospective randomized controlled clinical trial. ${ }^{20}$ Our findings are also in line with a recently published systematic literature review and meta-

Table 7. Heterotopic ossification at affected level $(N=221){ }^{a}$

\begin{tabular}{|c|c|c|c|c|c|}
\hline \multirow{2}{*}{$\begin{array}{l}\text { Heterotopic } \\
\text { Ossification }\end{array}$} & \multicolumn{5}{|c|}{ Visit } \\
\hline & Baseline & $3 \mathrm{mo}$ & $6 \mathrm{mo}$ & $12 \mathrm{mo}$ & $24 \mathrm{mo}$ \\
\hline $\begin{array}{l}\mathrm{n} \text { available } \\
\text { (missing) }\end{array}$ & 72 (149) & $168(55)$ & 75 (146) & 88 (133) & 107 (114) \\
\hline Grade 0 & $56(77.8)$ & $157(93.4)$ & $69(92.0)$ & $72(81.8)$ & $60(56.1)$ \\
\hline Grade I & $13(18.1)$ & $9(5.4)$ & $5(6.7)$ & $10(11.4)$ & 17 (15.9) \\
\hline Grade II & $3(4.2)$ & $1(0.6)$ & $1(1.3)$ & $2(2.3)$ & $9(8.4)$ \\
\hline Grade III & $0(0.0)$ & $0(0.0)$ & $0(0.0)$ & $4(4.5)$ & $13(12.1)$ \\
\hline Grade IV & $0(0.0)$ & $1(0.6)$ & $0(0.0)$ & $0(0.0)$ & $8(7.8)$ \\
\hline
\end{tabular}

Abbreviations: n, number of patients; N, number of levels.

${ }^{a}$ Results are written as n ( $\%$ available).
Table 8. Actions taken as a result of the adverse event.

\begin{tabular}{lc}
\hline Action Taken & No. $(\mathbf{\%}), \mathbf{n}=\mathbf{6 3}$ \\
\hline Invasive intervention & $14(22.2)^{\mathrm{a}}$ \\
$\quad$ Prestige disc explanted & $1(1.6)$ \\
Emergency room visit & $1(1.6)$ \\
Medication change & $15(23.8)$ \\
Diagnostic testing & $25(39.7)$ \\
Other & $12(19.0)$ \\
No action taken & $16(25.4)$
\end{tabular}

Abbreviation: n, number of patients.

aPercentages sum up to more than $100 \%$, as multiple answers were possible.

analysis in which the prevalence of $\mathrm{HO}$ after cervical artificial disc replacement within 1 to 2 years, 2 to 5 years, and 5 to 10 years of follow-up was $38.0 \%, 52.6 \%$, and $53.6 \%$, respectively, while the prevalence of severe HO was $10.9 \%, 22.2 \%$, and $47.5 \%$, respectively. ${ }^{21}$

On average, patients were discharged 4.8 days after surgery and returned to work 114 days after surgery. Time to discharge is greatly impacted by local practice and may be influenced by factors other than the patient's clinical recovery. A singlesite study in the Czech Republic reported a mean length of hospital stay of 3.7 days in patients undergoing cervical arthroplasty. ${ }^{15}$ Fifty-two percent of the patients returned to work after surgery, which is a slight decrease compared to the proportion working at baseline $(59.3 \%)$. Return to work data should be interpreted with caution, however, as many factors may affect a patient's work status, such as the patient's motivation; social factors, including proximity to retirement; and the nature of the work performed.

Twenty-three percent of the patients experienced one or more AEs, of which 6 were related to the Prestige disc, instrumentation, or procedure. One case of Prestige disc explant occurred 5 months after the Prestige implant surgery. Other studies have reported a similar rate of AEs. ${ }^{11,18,20}$ This supports the safety of the Prestige disc and that it is without major neurological, subsidence, and reoperation issues at 2- to 7-year follow-up.

Our study has a few limitations. The study findings are limited by the fluctuations in the number of patients at each visit during follow-up, which reduced the statistical power of the comparisons. Therefore, the observed results should be interpreted with caution. The range of motion and VAS for neck and arm pain was not reported consistently in the study sites, which prevented analysis of these outcomes. However, other measurements of quality of life (EQ-5D and NDI) 
showed that arthroplasty by Prestige was statistically and clinically improved.

\section{CONCLUSION}

This observational study describes the safety and effectiveness of arthroplasty in central and eastern Europe and the Middle East. Findings from this study are in line with published literature. QoL improvements, determined using the EQ-5D and NDI, were statistically and clinically significant 3 months after implantation, and these improvements were sustained to the last follow-up visit at 24 months with AE rates comparable to other total arthroplasty studies.

\section{ACKNOWLEDGMENTS}

The authors would like to thank all the study investigators for their contribution to the Prestige study and Amrita Ostawal (publications manager, Medtronic Clinical Spine, Bakken Research Center BV, The Netherlands) for publications management, medical writing, and editorial assistance.

\section{REFERENCES}

1. Mummaneni PV, Burkus JK, Haid RW, Traynelis VC, Zdeblick TA. Clinical and radiographic analysis of cervical disc arthroplasty compared with allograft fusion: a randomized controlled clinical trial. J Neurosurg Spine. 2007;6(3):198-209. https://doi.org/10.3171/spi.2007.6.3.198.

2. Nabhan A, Ahlhelm F, Pitzen T, et al. Disc replacement using Pro-Disc $\mathrm{C}$ versus fusion: a prospective randomised and controlled radiographic and clinical study. Eur Spine J. 2007;16(3):423-430. https://doi.org/10.1007/s00586-006-0226-5.

3. Silber JS, Anderson DG, Daffner SD, et al. Donor site morbidity after anterior iliac crest bone harvest for single-level anterior cervical discectomy and fusion. Spine (Phila Pa 1976). 2003;28(2):134-139.

4. König SA, Spetzger U. Clinical outcome of anterior cervical discectomy and fusion versus total disc replacement - a meta-analysis of 2532 cases. Neurosurgery. 2016;1(2).

5. Shaw JW, Johnson JA, Coons SJ. US valuation of the EQ-5D health states: development and testing of the D1 valuation model. Med Care. 2005;43(3):203-220.

6. Vernon H, Mior S. The neck disability index: a study of reliability and validity. $J$ Manipulative Physiol Ther. 1991;14(7):409-415.

7. Holte DC, O'Brien JP, Renton P. Anterior lumbar fusion using a hybrid interbody graft. a preliminary radiographic report. Eur Spine J. 1994;3(1):32-38. https://doi.org/10.1007/ BF02428314.

8. Mehren C, Suchomel P, Grochulla F, et al. Heterotopic ossification in total cervical artificial disc replacement. Spine
(Phila Pa 1976). 2006;31(24):2802-2806. https://doi.org/10. 1097/01.brs.0000245852.70594.d5.

9. Leung C, Casey AT, Goffin J, et al. Clinical significance of heterotopic ossification in cervical disc replacement: a prospective multicenter clinical trial. Neurosurgery. 2005;57(4):759-763, discussion 759-763.

10. Chen F, Yang J, Ni B, Guo Q, Lu X, Xie N. Clinical and radiological follow-up of single-level Prestige LP cervical disc replacement. Archives of Orthopaedic and Trauma Surgery. 2013;133(4):473-480. https://doi.org/10.1007/s00402-013-16896.

11. Peng CW, Yue WM, Basit A, et al. Intermediate results of the Prestige LP cervical disc replacement: clinical and radiological analysis with minimum two-year follow-up. Spine (Phila Pa 1976). 2011;36(2):E105-E111. https://doi.org/10. 1097/BRS.0b013e3181d76f99.

12. Stulik J, Kryl J, Sebesta P, Vyskocil T, Krbec M, Trc T. ProDisc-C mobile replacement of an intervertebral disc. A prospective mono-centric two-year study. Acta Chir Orthop Traumatol Cech. 2008;75(4):253-261.

13. Suchomel P, Jurak L, Benes V III, Brabec R, Bradac O, Elgawhary S. Clinical results and development of heterotopic ossification in total cervical disc replacement during a 4-year follow-up. Eur Spine J. 2010;19(2):307-315. https://doi.org/10. 1007/s00586-009-1259-3.

14. Hrabalek L, Vaverka M, Houdek M. Cervical disc arthroplasty (Prodisc-C): analysis of 3- to 4-year follow-up results. Rozhl Chir. 2009;88(11):634-641. [In Czech.]

15. Schluessmann E, Aghayev E, Staub L, et al. SWISSspine: the case of a governmentally required HTA-registry for total disc arthroplasty: results of cervical disc prostheses. Spine (Phila Pa 1976). 2010;35(24):E1397-E1405. https://doi.org/10. 1097/BRS.0b013e3181e0e871.

16. Hey HWD, Hong CC, Long AS, Hee HT. Is hybrid surgery of the cervical spine a good balance between fusion and arthroplasty? Pilot results from a single surgeon series. Eur Spine J. 2013;22(1):116-122. https://doi.org/10.1007/s00586012-2486-6.

17. Godil SS, Parker SL, Zuckerman SL, Mendenhall SK, McGirt M. Accurately measuring the quality and effectiveness of cervical spine surgery in registry efforts: determining the most valid and responsive instruments. Spine J. 2013;15(6):1203-1209. https://doi.org/10.1016/j.spinee.2013.07.444.

18. Fabrizi AP, Schiabello L. Prospective clinical results of 1 level cervical arthroplasty with the prestige device: four year results. Paper presented at: International Society for the Advancement of Spine Surgery (ISSAS13); April 3-5, 2013; Vancouver, BC, Canada.

19. Jin YJ, Park SB, Kim MJ, Kim KJ, Kim HJ. An analysis of heterotopic ossification in cervical disc arthroplasty: a novel morphologic classification of an ossified mass. Spine $J$. 2013;13(4):408-420. https://doi.org/10.1016/j.spinee.2012.11.048.

20. Burkus JK, Traynelis VC, Haid RW Jr, Mummaneni PV. Clinical and radiographic analysis of an artificial cervical disc: 7year follow-up from the Prestige prospective randomized controlled clinical trial: clinical article. J Neurosurg Spine. 2014;21(4):516-528. https://doi.org/10.3171/2014.6.SPINE13996.

21. Kong L, Ma Q, Meng F, Cao J, Yu K, Shen Y. The prevalence of heterotopic ossification among patients after cervical artificial disc replacement: a systematic review and 
meta-analysis. Medicine (Baltimore). 2017;96(24):e7163. https://doi.org/10.1097/MD.0000000000007163.

Disclosures and COI: Marton Ronai, MD: Dr Rónai reports personal fees from Medtronic Trading NL BV during the conduct of the study; personal fees from Medikomp $\mathrm{Kft}$, outside the submitted work; and travel, hotel, and registration payed by Medtronic for attending Summer University July 1-3, 2015, Vienna, Austria. Dated May 6, 2016. Jiri Matejka, MD: Dr Matejka reports receiving financial support or services from Medtronic during the conduct of the study. Dated May 2, 2016. The study sponsor (Medtronic Clinical Spine, Bakken Research Center BV, The Netherlands) established subcontracts to the participating research sites and/or investigators. Research support for this study was provided by Medtronic
Clinical Spine, Bakken Research Center BV, The Netherlands. The study was presented in part at EuroSpine and NASS meetings during 2015. No other conflicts of interest were declared.

Corresponding Author: Saleh Baeesa, MD, FRCSC, Division of Neurosurgery, Faculty of Medicine, King Abdulaziz University, Jeddah, Saudi Arabia. Phone: +966126408346; Email: sbaeesa@kau.edu.sa.

Published 30 June 2019

This manuscript is generously published free of charge by ISASS, the International Society for the Advancement of Spine Surgery. Copyright (c) 2019 ISASS. To see more or order reprints or permissions, see http://ijssurgery.com. 